\title{
Alzheimer's disease markers in the aged sheep (Ovis aries)
}

"Suzanne J. Reid" , "Natasha E Mckean", Kristen Henty", Erik Portelius ${ }^{\text {b,c }}$, Kaj Blennow ${ }^{\text {b,c }}$, Skye

R. Rudiger ${ }^{d}$, C. Simon Bawden ${ }^{d}$, Renee R. Handley ${ }^{a}$, Paul J. Verma ${ }^{d}$, Richard L.M. Faulle, Henry J. Waldvogel ${ }^{\mathrm{e}}$, Henrik Zetterberg ${ }^{\mathrm{b}, \mathrm{c}, \mathrm{f}}$, Russell G. Snell ${ }^{\mathrm{a} *}$

a. The Neurogenetics Group, School of Biological Sciences, University of Auckland, Auckland, New Zealand. Suzanne Reid: s.reid@auckland.ac.nz; Natasha Mckean: nmck309@aucklanduni.ac.nz; Kristen Henty: k.henty@auckland.ac.nz; Renee R. Handley: r.handley@auckland.ac.nz; Russell Snell: $\underline{\text { r.snell@auckland.ac.nz. }}$

b. Institute of Neuroscience and Physiology, Department of Psychiatry and Neurochemistry, the Sahlgrenska Academy at the University of Gothenburg, Mölndal, Sweden (erik.portelius@neuro.gu.se; kaj.blennow@neuro.gu.se, henrik.zetterberg@clinchem.gu.se)

c. Clinical Neurochemistry Laboratory, Sahlgrenska University Hospital, Mölndal, Sweden (erik.portelius@neuro.gu.se; kaj.blennow@neuro.gu.se, henrik.zetterberg@clinchem.gu.se)

d. Molecular Biology and Reproductive Technology Laboratories, Livestock and Farming Systems Division, South Australian Research and Development Institute, Roseworthy, South Australia 5371. Skye Rudiger: Skye.Rudiger@sa.gov.au; Simon Bawden: Simon.Bawden@sa.gov.au; Paul Verma: Paul.Verma@sa.gov.au. 
e. Department of Anatomy and Medical Imaging and The Centre for Brain Research, Faculty of Medical and Health Sciences, The University of Auckland, Auckland, New Zealand. Richard Faull: rlm.faull@auckland.ac.nz; Henry Waldvogel:

h.waldvogel@auckland.ac.nz.

f. Department of Molecular Neuroscience, UCL Institute of Neurology, Queen Square, London, UK. Henrik Zetterberg: henrik.zetterberg@clinchem.gu.se.

*Corresponding Author: Russell Snell r.snell@auckland.ac.nz

\#Authors contributed equally 


\section{Abstract}

This study reports the identification and characterisation of markers of Alzheimer's disease (AD) in aged sheep (Ovis aries) as a preliminary step towards making a genetically modified large animal model of AD. Importantly, the sequences of key proteins involved in AD pathogenesis are highly conserved between sheep and human. The processing of the amyloid- $\beta(A \beta)$ protein is conserved between sheep and human, and sheep $A \beta_{1-42} / A \beta_{1-40}$ ratios in cerebrospinal fluid (CSF) are also very similar to human. In addition, total-tau and neurofilament light levels in CSF are comparable to those found in human. The presence of neurofibrillary tangles in aged sheep brain has previously been established; here we report for the first time that plaques, the other pathological hallmark of $A D$, are also present in the aged sheep brain. In summary, the biological machinery to generate the key neuropathological features of $A D$ is conserved between the human and sheep, making the sheep a good candidate for future genetic manipulation to accelerate the condition for use in pathophysiological discovery and therapeutic testing.

Keywords: Alzheimer's Disease, Amyloid- $\beta$, Sheep Ovis aries, Plaques, Tangles, Animal model. 


\section{Introduction}

Dementia is the most common neurological condition among older adults, with the majority of cases being attributable to Alzheimer's disease (AD). AD is a devastating neurodegenerative disease that causes progressive memory loss, cognitive decline and finally dementia, leading to premature death and causing considerable stress to families. The prevalence of AD is expected to triple by 2050 due to an aging population (Alzheimers Ass. 2016, Alzheimers 2012) and therefore effective treatments for the disease are desperately needed. Mutations in three genes; amyloid precursor protein (APP), and presenilin 1 and 2 (PSEN1 and PSEN2) (Levy-Lahad et al., 1995, Levy et al., 1990, Sherrington et al., 1995) are known to cause relatively rare $(<1 \%)$ familial AD. Each of these mutations result in the enhanced production of, or imbalances favouring, the amyloidogenic 42 amino acid long amyloid- $\beta$ peptide $(A \beta 42)$ form of the APP protein. The risk of developing sporadic or late onset $A D(L O A D)$ has been associated with variations in several genes including apolipoprotein E (APOE) (Harold et al., 2009, Saunders et al., 1993, Schellenberg and Montine 2012). These genes are also functionally linked to A $\beta$ peptide homeostasis, supporting the 'amyloid cascade hypothesis' as an initiating mechanism for AD pathogenesis (Hardy and Higgins 1992).

Due to the difficulty of making a diagnosis of $A D$ in the earlier phases of the disease, patients recruited for clinical trials have typically been in the mild to moderate dementia stages of the disease (Blennow 2010). However it is generally agreed that the most effective treatment window would be early and ideally pre-symptomatic (Mangialasche et al., 2010). Cerebrospinal fluid (CSF) biomarkers are increasingly being used in the diagnosis of AD and also in the mild cognitive impairment ( $\mathrm{MCl}$ ) phase of $A D$ (Blennow et al., 2010). These 
biomarkers are also central in the recent research criteria for AD (Dubois et al., 2014) and preclinical AD (Dubois et al., 2016). Late-onset neurodegenerative diseases such as AD are difficult to model accurately in rodents because of their short lifespans. The commonly used rodent models of $A D$ have been engineered to exhibit rapid and unnatural disease progression (Sabbagh et al., 2013), limiting their applications for early-stage disease research. Indeed, while several compounds have been beneficial in mouse models of AD, translation to humans has been very disappointing (Blennow K 2006, Dragunow 2008, McGonigle 2014). Successfully translated compounds have been those providing symptomatic relief rather than halting disease progression (McGonigle 2014).

To enable safer, more effective clinical trials, and to discover the early pathogenic mechanisms of $A D$ we believe there is a need for a large animal model of $A D$, with a complex brain structure (including a more developed cortex with gyri and sulci) and longevity, which will accurately capture the disease as it progresses, including its presymptomatic phase. Dogs and non-human primates have been used as models of aging and show relevant AD pathology, as recently reviewed (Youssef et al., 2016); however these models are expensive and fraught with ethical issues. A transgenic AD minipig has been produced by random integration of mutant human APP into the minipig genome, driven by the PDGF $\beta$ promoter to give high levels of expression (Kragh et al., 2009, Sondergaard et al., 2012). Minipigs are housed individually or in small groups, making long-term pre-clinical trials relatively expensive.

We see value in modelling $A D$ in sheep (Ovis aries) due to the similarity of its brain structure and size relative to human. Sheep can live for at least 10 years, making them ideal for the study of later-onset diseases such as AD. Importantly, studies have shown AD-associated 
neurofibrillary accumulation (tau pathology) in normal aged sheep (Braak et al., 1994, Nelson and Saper 1995); a feature which is absent in wild type rodents and has made AD modelling challenging in rats and mice (Hardy and Selkoe 2002). While the rate of naturally occurring dementia in sheep is unknown (as most farmed sheep are culled before reaching old age), sheep with cognitive deficits are studied due to natural mutations in genes causing Battens Disease in humans (Cook et al., 2002, Jolly et al., 1980, Weber and Pearce 2013) Sheep are readily trainable for use in tests of cognitive function (Morton and Avanzo 2011) and sheep suffering from a progressive neurological disease can be quantified longitudinally using modern methods, such as EEG (Perentos et al., 2015) and MRI (Sawiak et al., 2015). Sheep have face recognition systems for remembering specific individuals long term comparable to human (Kendrick et al., 2001). Furthermore, sheep can be kept in large numbers in a social environment on a farm, which is ethically more acceptable and cheaper than caged large laboratory animals. Genetically modified flocks can also be expanded relatively quickly from a few founder animals due to the JIVET reproductive technology that has been developed specifically in sheep (Kelly et al., 2005). A transgenic sheep model of the neurodegenerative disorder, Huntington's Disease, has been successfully established by our laboratory in this manner (Jacobsen et al., 2010) and is proving to be a valuable tool in HD research (Handley et al., 2016, Morton et al., 2014, Reid et al., 2013). The sheep genome has now been published and annotated (Jiang et al., 2014), and thus the genome of the sheep can now be precisely manipulated for human disease research.

In this report, we present data on the suitability of sheep as a model for AD. We compare the human and sheep peptide sequences for relevant AD proteins and peptides, and compare types and levels of common AD biomarkers in CSF that will be relevant for tracking 
disease progression. We also looked for evidence of plaques and tangles, the hallmarks of human $A D$, in the aged sheep brain.

\section{Methods}

\subsection{Human and sheep DNA sequence alignments}

Key human AD-associated reference protein sequences (as at $26^{\text {th }}$ July 2016 ) were used in BLAST analysis (utilising the blastp algorithm) against all Ovis aries protein sequences. Where proteins have multiple isoforms, the longest recorded isoform for human was used. For the APP protein, cleavage sites were compared, as well as the amino acid sequence of the $A \beta_{1-42}$ fragment. The sheep protein with the highest homology against each human sequence is presented in Table 1.

\subsection{Collection of tissue and CSF samples}

Samples were obtained from four eight-year-old sheep, and a single fourteen-year-old sheep that were being euthanized for normal animal management reasons. Animals were humanely euthanized followed by immediate exsanguination. CSF samples were immediately collected from cisterna magna of each of the eight year old sheep, aliquoted and frozen. After extraction from the skull, the brains from all five sheep were blocked into five coronal blocks, split into two hemispheres and immersion fixed for 48 hours in $10-20$ volumes of freshly prepared $10 \%$ buffered $(0.1 \mathrm{M}$ phosphate buffer $\mathrm{pH}$ 7.4) formalin (Scharlau, Spain) at $4^{\circ} \mathrm{C}$ and then transferred to $0.1 \mathrm{M}$ phosphate buffer plus $0.1 \%$ sodium azide (Sigma, Australia). Fixed blocks were then cryopreserved for immunohistochemical analysis using sequential sucrose immersion 
followed by freezing in dry ice powder prior to storage at $-80^{\circ} \mathrm{C}$ as previously described (Waldvogel et al., 2007).

\subsection{Fluid biomarkers in sheep CSF}

\subsubsection{Hybrid immunoaffinity-mass spectrometry for $A \beta$}

To identify A $\beta$ fragments, we used CSF taken from each of the eight year old sheep. Immunoaffinity capture of $A \beta$ was combined with mass spectrometry (MS) for analysis and study of the $A \beta$ peptide pattern in sheep CSF as previously described (Portelius et al., 2007). In brief, the anti-A $\beta$ antibodies $6 \mathrm{E} 10$ and $4 \mathrm{G} 8$ were separately coupled to magnetic beads. After washing of the beads, the $4 \mathrm{G} 8$ and $6 \mathrm{E} 10$ coated beads were used in combination for immunoprecipitation. After elution, the immune-purified $A \beta$ peptides were identified using an UltraFlextreme matrix-assisted laser desorption/ionization time-of-flight (MALDI-TOF) MS instrument (Bruker Daltonics, Bremen, Germany).

\subsubsection{Total tau and phospo-tau181 concentrations}

Total tau concentration in CSF was measured using using a sandwich enzyme-linked immunosorbent assay (ELISA) (INNOTEST hTAU-Ag; Fujirebio, Ghent, Belgium) that uses antibodies against the mid-domain of tau, thus measuring all tau isoforms irrespective of phosphorylation state. Phospho-tau181 concentration in CSF was measured using a sandwich ELISA (INNOTEST Phospho-tau[181P]; Fujirebio, Ghent, Belgium) that includes one antibody specific for the phospho-epitope at threonine 181 in combination with a mid- 
domain anti-tau antibody. Intra-assay coefficients of variation were below $10 \%$ and all samples measured within the linear range of the standard curve.

\subsubsection{Neurofilament light concentration}

Neurofilament light concentration in CSF was measured using the NF-light ELISA as described by the manufacturer (UmanDiagnostics, Umeå, Sweden). The assay uses two monoclonal antibodies directed against the rod domain of the protein. The lower limit of quantification is $50 \mathrm{ng} / \mathrm{L}$ with intra-assay coefficients of variation $<10 \%$.

\subsection{Tangles and plaques in the sheep brain}

Coronal brain sections at the level of mid temporal gyrus and hippocampus were cut on a freezing sledge microtome and stored in phosphate buffered saline (PBS) plus $0.1 \%(\mathrm{w} / \mathrm{v})$ azide (Sigma, Australia) at $4^{\circ} \mathrm{C}$ until use. For immunohistochemistry, free floating $50 \mu \mathrm{m}$ thick sections were initially washed in a solution of $50 \%$ methanol (Scharlau, Spain) and $1 \%$ $\mathrm{H}_{2} \mathrm{O}_{2}$ to expose binding sites and block endogenous peroxidase activity. Sections were washed in PBST (PBS with $0.2 \%$ triton $\mathrm{X}-100(\mathrm{BDH}, \mathrm{NZ})$ ) prior to incubation in primary antiserum diluted in immunobuffer, (1\% Normal Goat Serum in PBS,0.2\% Triton-X100 and $0.4 \mathrm{~g}$ Methiolate, (Waldvogel et al., 2007) for 48 hours at $4^{\circ} \mathrm{C}$. To visualise tangles, we used a polyclonal rabbit anti-Tau antibody (DAKO \#A0024 diluted 1:15,000) generated against the C-terminus of human Tau (amino acids 243-445). Plaques were visualised using a monoclonal mouse anti-A $\beta$ antibody (clone 4G8, Chemicon \#MAB1561, diluted 1:1200) raised to amino acids 17-24 of $A \beta$, with the epitope between aa18-22. Sections were subsequently washed in PBST at room temperature and incubated for 24 hours at room 
temperature in the appropriate biotinylated goat anti-mouse or goat anti-rabbit secondary antibody (Sigma, Australia), diluted to 1:1000 in immunobuffer. Subsequently, sections were washed with PBST and incubated for four hours at room temperature in extravidin peroxidase complex (Sigma, E2886, Australia), diluted to 1:1000 in immunobuffer. Sections had a further three 10 minute washes in PBST prior to visualisation. For visualisation, each series of sections was incubated in $0.05 \%$ diaminobenzidine tetrahydrochloride (DAB, Sigma, Australia) in phosphate buffer with the addition of $0.01 \% \mathrm{H}_{2} \mathrm{O}_{2}(\mathrm{BDH}, \mathrm{NZ})$ to visualize the tertiary complex. Subsequently, sections were mounted onto slides with gelatine, dried overnight and then dehydrated in a graded ethanol and xylene series. Sections were cover-slipped with DPX Mountant solution (Merck, Australia) prior to visualization. Negative control sections were processed to determine nonspecific staining using the same immunohistochemical procedures as detailed above, except that the primary or secondary antibodies were omitted from the procedure. Positive human controls were used for each antibody for comparison. Sections were Nissl stained with cresyl violet (Sigma, Australia) according to standard techniques $(0.5 \% \mathrm{w} / \mathrm{v})$, to assist in identifying the plane of cells relative to plaques and tangles, and to assist in identification of cell layers.

Tangles and plaques were visualised on a Leica DC 500 light microscope with Analysis LS Research 2.3 software, and the total number of tangles and plaques in the entire cortical region and hippocampus per slide were counted. The number per location (gyrus) was noted for each sheep, and nissl-stained nuclei enabled assessment with respect to cortical layers. As sample sizes were small and because of some inter-animal variability of the specific hippocampal region sections examined, a relative rather than absolute count was 
generated for each animal (marked with a + sign; Table 3). Tangle densities, representative of all 5 sheep, were mapped on a MSU atlas image of the sheep brain (section 1240 from the Michigan State University Sheep Brain Atlas(Johnson et al., ). The hippocampal level seen in this MSU atlas image in Figure 3 differs between the left and right hemispheres, representing the range of sections examined in this study and also reflecting the difficulty in collecting comparative coronal sections from the hippocampal formation.

Thioflavin T staining (Sigma) was undertaken on $20 \mu \mathrm{m}$ sections which were mounted, dehydrated and then stained for eight minutes in $0.05 \%$ thioflavin solution followed by three washes in PBS solution. After adding coverslips the slides were viewed via fluorescence microscopy under a Leica DC 500 microscope with Analysis LS Research 2.3 software. Human sections were processed in parallel as positive control comparisons. 


\section{Results}

\subsection{Homology of Key AD proteins between human and sheep}

The amino acid sequences of the key AD-related proteins show high homology between human and sheep, several close to $100 \%$ (Table 1). As seen in humans, sheep have multiple isoforms of APP. There were 6 predicted sheep isoforms for APP, ranging from 677 - 770 amino acid residues. There are 23 amino acid differences within the full length APP protein compared, however none of these are close to the C-terminal cleavage sites. The sheep $A \beta_{1-}$ 42 mRNA region has 6 nucleotide differences when compared to human, but results in a peptide sequence which is $100 \%$ homologous. BACE1, the $\beta$-cleavage enzyme which contributes to formation of the disease-associated $A \beta_{1-42}$ fragment, is $98.4 \%$ homologous between human and sheep. Presenilin 1 and Presenilin 2; components of the gammacleavage complex, also show high homology. Ovine NF-L homology to human is $95.3 \%$. A 10 amino acid insertion in the sheep sequence interrupts an otherwise $97.1 \%$ homology. The sheep ApoE protein had the lowest homology to humans overall (70\%), however it does possess the same amino acids in the key positions (112 and 158) that define the human $A P O E$ \&4 allele.

\section{2. $A \beta$ and Tau levels in sheep CSF}

\subsubsection{Ab levels in sheep CSF}

All of the main fragments of APP that are found in humans were detectable in sheep CSF, including $A \beta_{1-42}$ (Figure 1). As seen in humans (Figure 1E), the $A \beta_{1-17}$ and $A \beta_{1-40}$ peptides were the most abundant cleavage products. The ratio of $A \beta_{1-42}$ over $A \beta_{1-40}$ averaged at 0.113 
for the sheep, which is very similar to the human ratio of $A \beta_{1-42}$ over $A \beta_{1-40}$ (Hansson et al., 2007), indicating the utility of sheep CSF as a tool for following AD progression.

\subsubsection{Tau and phosho-tau181 processing in sheep CSF}

Levels of total tau were variable within the three sheep CSF samples assessed (Table 2), but were comparable with human samples, and average $319.3 \mathrm{ng} / \mathrm{L}$, which is within the normal range for humans (Sjögren et al., 2001). Levels of phospho-tau181 in sheep CSF were very low, the mean level in normal humans is around $45 \mathrm{ng} / \mathrm{L}$ (Vanderstichele et al., 2006), and all three sheep samples were within 15.1 - $15.4 \mathrm{ng} / \mathrm{L}$, which was close to the lower limit of quantification for the assay.

\subsubsection{Neurofilament light in sheep CSF}

Levels of neurofilament light were between 600 and $1200 \mathrm{ng} / \mathrm{L}$ in all sheep samples (Table 2) which is within the normal range seen in humans (Zetterberg et al., 2016).

\subsection{Plaques in the sheep brain}

$A \beta$ immunopositive plaques were identified in all animals and were visualised as large dense structures many times larger than a single neuron as shown in Figure $2 \mathrm{~A}-\mathrm{C}$, as well as abundant smaller structures about the size of a single neuronal nucleus (Figure 2A, arrow). Quantification of plaques was limited to large dense structures and excluded the smaller structures which were very numerous, particularly in supragranular cortical layers. Plaques were found in both supragranular and infragranular layers within each of the sheep and in all cortical regions, including the hippocampus. The plaques observed within each sheep 
were present at similar densities in all cortical areas, and the average number of plaques per slide in each sheep ranged between 60 and 109, equating to an average of 24-44 plaques per $\mathrm{cm}^{2}$ of cortical tissue. Most of the plaques were diffuse, although a few resembled the dense-core plaques seen in the positive human control. Thioflavin-T stained structures were seen in all of the sheep (Figure 2D), although at considerably lower abundance than of those seen with immunostaining. The human positive control sections contained large numbers $(>500)$ immuno-stained plaques, with adjacent sections revealing many $(>100)$ thioflavin positive structures similar to those seen in the sheep.

\subsection{Tangles in the sheep brain}

Tangles were identified in fixed brain tissue from the five aged sheep using Tau antibodies. A range of tau immunopositive structures were detected in all of the sheep assessed, and included small neuropil threads to the larger classical tangles shown in Figure 3A and B. There was some evidence for dystrophic neurites, based on thickened neurites seen within tau labelled sections (Figure 3C), although as we did not double stain the sections we cannot confirm their association with plaques. The tangle structures were almost exclusively within the upper middle layers (layer II - IV) of the sheep cortex and most abundant in the temporal lobe and entorhinal cortex of all sheep than elsewhere in the section (Figure 3D). Tangle-like structures were not identified in the hippocampus of the fourteen-year-old sheep, but were detected in 3 of the 4 eight-year old sheep. All sheep had tangles within entorhinal cortex. Quantification of tangles was limited to the larger neuronal tangles, excluding neuropil threads, which were very numerous. The average number of tangles per slide for each sheep ranged between 3 and 58. 


\section{Discussion}

The aim of this study was to assess the suitability of sheep for future genetic manipulation to produce a large animal model of AD. We examined the similarities between key human and sheep proteins known to be involved in AD, and measured CSF levels of proteins and peptides that are known to be associated with the disease. Additionally, we report evidence of plaques and tangles; the neuropathological hallmarks of the disease, in the aged sheep brain.

Aged sheep naturally develop the PHF-tau positive tangles associated with $A D$, as seen in our and previous studies (Braak et al., 1994, Nelson and Saper 1995). Our identification of tangle structures in entorhinal cortex from all animals and within hippocampus of three of the five animals is consistent with the progression of tangles in human brain described in Serono Pozo et al (2011) and Braak and Braak (2006). Levels of CSF total tau in normal sheep are shown here to be comparable to that found in humans. In contrast, phospho-tau181 concentrations were below the limit of quantification in sheep CSF. The amino acid threonine that is phosphorylated at this position is present in the sheep peptide, but the flanking region in the sheep tau amino acid sequence differs from human tau. This sequence divergence may mean that phosphorylation at tau181 cannot take place, or alternatively, that the AT270 antibody used, with a minimal epitope of $\mathrm{P}_{176}$ PAPKT(p)P 182 (Vanmechelen et al., 2000), does not react with sheep tau phosphorylated at this position. Either way, the ratio of total tau to phospho-tau181 cannot be used as a biomarker or indicator of disease progression in sheep. However, the human tau protein can potentially be phosphorylated at 19 sites or more (Augustinack et al., 2002), and because tau tangles do form in the sheep 
brain, phosphorylation of other sites may be more suitably used to track disease progression, such as phospho-tau231 (Hampel et al., 2010). Neurofilament light levels in human CSF can also potentially be used as a biomarker of AD progression (Zetterberg et al., 2016), and our results show that neurofilament light can be detected and measured in sheep, and is found at levels comparable to that of humans.

The $A \beta$ fragments detected in CSF from the four eight-year-old sheep show that sheep utilise the same mechanisms for degrading APP and $A \beta$ peptide as humans, which is a major part of the amyloid cascade hypothesis. Importantly, we have identified that sheep produce the disease associated $A \beta_{1-42}$ fragment, suggesting they will be a good model for testing the amyloid cascade hypothesis of $A D$. The $A \beta_{1-42}$ peptide sequence is completely conserved between humans and sheep. Mice and rats show a three amino acid difference in the $A \beta_{1-42}$ peptide sequence (Johnstone et al., 1991), suggesting that sheep may make a more comparable model to humans than rodent models. Our results show that the $\alpha-, \beta$ - and $\gamma^{-}$ secretase cleavage sites, and processing pathways, in the APP protein are most likely identical between sheep and humans (Portelius et al., 2011). This evidence, taken together, suggests that sheep should be able to form the amyloid plaques that define $A D$, indeed, here we report for the first time the presence of plaques in sheep brain tissue, detected by $A \beta$ immunohistochemistry. Although the sample size in this study was limited, the fourteenyear-old sheep showed more plaques than any of the four eight-year-old sheep (Table 3), suggesting that plaques are likely to accumulate in an age-dependant manner in sheep as they do in humans. The relatively low thioflavin staining in sheep compared to human may be due to most of the plaques in sheep being diffuse rather than dense-cored plaques, as it 
was the dense centres that showed the strongest thioflavin staining in human positive control sections.

All of the key proteins implicated in human $A D$ are found in sheep and show high homology. Interestingly, the ApoE amino acid sequence in sheep contains two amino acids at the 112 and 158 positions, which correspond with the $A P O E \varepsilon 4$ allele in humans that is known to increase the chances of developing $A D$.

The evidence presented here suggests that the amyloid pathway has been highly conserved between humans and sheep, and that the pathological mechanisms for human AD are likely also found in sheep. Sheep are not known to develop AD naturally, although this is likely due to their shorter lifespan relative to humans. Most sheep in typical farming conditions are culled once past their useful lifespan for the farmer, and so do not die of age related disorders.

Our findings demonstrate that sheep are a clinically translatable model, displaying the pathological hallmarks of $A D$, and are thus a good species for consideration of genetic manipulation to generate a large animal model of AD. Because of the conservation of the key constituents of the amyloid generating pathway an approach would be to introduce a mutation through gene editing in APP, PSEN1 or 2 that results in early onset human disease. As the typical $A D$ pathogenic markers are present in aged wild-type sheep our expectation is that a model made in this way without overexpression of transgenes or using multiple mutations will develop early AD changes. The indication that prodromal disease status could be monitored via CSF testing dramatically improves the potential utility of a sheep AD model. Moreover, the ability to keep sheep in large cohorts in standard paddocking 
arrangements will enable research and drug testing at lower cost, hopefully bringing the field of $A D$ research closer to finding an effective cure.

\section{Acknowledgments}

We thank the Freemasons of New Zealand for their support and funding for this project. $\mathrm{HZ}$ is supported by the Knut and Alice Walleberg Foundation, the Swedish Research Council and the European Research Council. KB is supported by the Swedish Research Council, the Swedish Alzheimer Foundation, the Swedish Brain Foundation and the Torsten Söderberg Foundation.

\section{Conflicts of interest}

The authors have no conflicts of interest to declare. 


\section{Tables}

Table 1: Percentage identity between key human AD-related proteins and the sheep reference sequence or closest sheep sequence hit on BLAST, showing that high homology exists between human and sheep.

\begin{tabular}{|c|c|c|c|c|}
\hline & $\begin{array}{c}\text { Sheep vs Human \% } \\
\text { Identity }\end{array}$ & $\begin{array}{c}\text { Human Sequence } \\
\text { (Length) }\end{array}$ & Sheep Sequence (Length) & $\begin{array}{c}\text { Coverage } \\
\%\end{array}$ \\
\hline APP770 & $97 \%$ & NP_000475.1(770) & XP_004002849.1 (770) & 100 \\
\hline$A \beta 1-40$ & $100 \%$ & NP_000475.1 (770) & XP_004002849.1(770) & 100 \\
\hline$A \beta 1-42$ & $100 \%$ & NP_000475.1 (770) & XP_004002849.1 (770) & 100 \\
\hline$\alpha$-cleavage site & $100 \%$ & NP_000475.1 (770) & XP_004002849.1 (770) & 100 \\
\hline$\beta$-cleavage site & $100 \%$ & NP_000475.1 (770) & XP_004002849.1 (770) & 100 \\
\hline$\gamma$-cleavage sites & $100 \%$ & NP_000475.1 (770) & XP_004002849.1 (770) & 100 \\
\hline BACE1 & $99 \%$ & NP_036236.1(501) & XP_004016104.1 (501) & 100 \\
\hline PSN1 & $91 \%$ & NP_000012 (467) & XP_012037385.1 (468) & 100 \\
\hline PSN2 & $96 \%$ & NP_000438.2 (448) & XP_014954666.1 (445) & 100 \\
\hline APOE & $69 \%$ & NP_000032.1 (317) & XP_011950465.1 (342) & 100 \\
\hline APOE4 (112 position) & $100 \%$ & NP_000032.1 (317) & XP_011950465.1 (342) & 100 \\
\hline APOE4 (158 position) & $100 \%$ & NP_000032.1 (317) & XP_011950465.1 (342) & 100 \\
\hline Tau isoform 1 (758aa) & $87 \%$ & NP_058519.3 (758) & XP_012004971.1 (601) & 80 \\
\hline NF-L & $98 \%$ & NP_006149.2 (543) & XP_014948576.1 (536) & 75 \\
\hline
\end{tabular}


Table 2: CSF levels of three protein fragments associated with AD. Total tau and neurofilament light levels were measurable in sheep and comparable to human levels, while levels of Phospho-tau 181 were not much higher than the lower level quantification limits of the test.

\begin{tabular}{cccc}
\hline & & Phospho-Tau181 & Neurofilament \\
& Total Tau (ng/L) & (ng/L) & Light (ng/L) \\
Sheep 1 & 594 & 15.1 & 800 \\
Sheep 2 & 73 & 15.4 & 615 \\
Sheep 3 & 291 & 15.1 & 1185 \\
\hline
\end{tabular}




\section{Figure Legends (images as separate TIFF files)}

Figure 1: Amyloid-beta CSF profiles, showing that all of the cleaved fragments of the APP protein present in humans appear in similar levels in sheep, including the $A \beta_{1-42}$ fragment. AD represent the four eight year old sheep samples, with $\mathbf{E}$ as a human control for comparison.

Figure 2: Plaques are present in aged sheep brain. A. Large amyloid immuno-positive structures are observed in the entorhinal cortex of the 14 year old sheep along with smaller structures indicated by the arrow. B. High magnification image of the largest plaque seen in A. C. Two plaques adjacent to granule cells of dentate gyrus within the hippocampus from 8 year old sheep 3. DAB is the chromogen used in A, B and C. D. A thioflavin-positive structure from the 14 year old sheep cortex is shown. Scale bars are $50 \mu \mathrm{m}$ in length.

Figure 3: Tangles are present in the aged sheep brain. A. A neuronal tangle found in the entorhinal cortex of the 14 year old sheep. B. A tangle within the temporal lobe of 8 year old Sheep 2. C. Possible dystrophic neurites in the 14 year old sheep observed as a cluster of thickened neurites within entorhinal cortex. $D A B$ is the chromogen used in A, B and C. D. Section 1240 from the Michigan State University Sheep Brain Atlas is representative of the coronal level of hippocampus examined in this study showing relative densities of tangles in different regions of the cortex. Red circles represent high density; yellow represents moderate density, and green is low density. Scale bars are $50 \mu \mathrm{m}$ in length. 
Table 3: Relative numbers of tangles and plaques observed in the cortex and hippocampus of the 5 sheep in this study, showing that the fourteen year old sheep had more tangles and plaques than the eight year old sheep. One + equates to approximately 5 plaques or tangles.

Average No. of Tangles per $50 \mu \mathrm{m}$

$\begin{array}{lll}\text { 8yo Sheep } 1 & + & ++++++++++++ \\ \text { 8yo Sheep } 2 & ++++ & +++++++++++++++ \\ \text { 8yo Sheep } 3 & + & +++++++++++ \\ \text { 8yo Sheep } 4 & + & ++++++++++++++ \\ \text { 14yo Sheep } & +++++++++++ & +++++++++++++++++++++\end{array}$




\section{References}

Alzheimers Ass. 2016. 2016 ALZHEIMER'S DISEASE FACTS AND FIGURES [Alzheimer's Association National Office, 225 N. Michigan Ave., FI. 17, Chicago, IL 60601 http://www.alz.org/facts/overview.asp

Alzheimers, N.Z. 2012. Updated Dementia Economic Impact Report, 2011, New Zealand [New Zealand. http://www.alzheimers.org.nz/news-info/nz-information/dementia-economicreport-2012

Augustinack, J.C., Schneider, A., Mandelkow, E.-M., Hyman, B.T. 2002. Specific tau phosphorylation sites correlate with severity of neuronal cytopathology in Alzheimer's disease. Acta Neuropathologica 103(1), 26-35. doi:10.1007/s004010100423.

Blennow, K. 2010. Biomarkers in Alzheimer's disease drug development. Nature medicine 16(11), 1218-22.

Blennow K, d.M., Zetterberg H 2006. Alzheimer's disease. The Lancet 368, 387-403.

Blennow, K., Hampel, H., Weiner, M., Zetterberg, H. 2010. Cerebrospinal fluid and plasma biomarkers in Alzheimer disease. Nature Reviews Neurology 6(3), 131-44.

Braak, H., Braak, E., Strothjohann, M. 1994. Abnormally phosphorylated tau protein related to the formation of neurofibrillary tangles and neuropil threads in the cerebral cortex of sheep and goat. Neurosci Lett 171(1-2), 1-4.

Cook, R.W., Jolly, R.D., Palmer, D.N., Tammen, I., Broom, M.F., McKinnon, R. 2002. Neuronal ceroid lipofuscinosis in Merino sheep. Australian veterinary journal 80(5), 292-7.

Dragunow, M. 2008. The adult human brain in preclinical drug development. Nat Rev Drug Discov 7(8), 659-66. doi:10.1038/nrd2617.

Dubois, B., Feldman, H.H., Jacova, C., Hampel, H., Molinuevo, J.L., Blennow, K., DeKosky, S.T., Gauthier, S., Selkoe, D., Bateman, R. 2014. Advancing research diagnostic criteria for Alzheimer's disease: the IWG-2 criteria. The Lancet Neurology 13(6), 614-29.

Dubois, B., Hampel, H., Feldman, H.H., Scheltens, P., Aisen, P., Andrieu, S., Bakardjian, H., Benali, H., Bertram, L., Blennow, K. 2016. Preclinical Alzheimer's disease: Definition, natural history, and diagnostic criteria. Alzheimer's \& Dementia 12(3), 292-323.

Hampel, H., Blennow, K., Shaw, L.M., Hoessler, Y.C., Zetterberg, H., Trojanowski, J.Q. 2010. Total and phosphorylated tau protein as biological markers of Alzheimer's disease. Experimental gerontology 45(1), 30-40. doi:10.1016/j.exger.2009.10.010.

Handley, R.R., Reid, S.J., Patassini, S., Rudiger, S.R., Obolonkin, V., McLaughlan, C.J., Jacobsen, J.C., Gusella, J.F., MacDonald, M.E., Waldvogel, H.J., Bawden, C.S., Faull, R.L., Snell, R.G. 2016. Metabolic disruption identified in the Huntington's disease transgenic sheep model. Sci Rep 6, 20681. doi:10.1038/srep20681.

Hansson, O., Zetterberg, H., Buchhave, P., Andreasson, U., Londos, E., Minthon, L., Blennow, K. 2007. Prediction of Alzheimer's disease using the CSF A $42 / A \beta 40$ ratio in patients with mild cognitive impairment. Dementia and geriatric cognitive disorders 23(5), 316-20.

Hardy, J., Selkoe, D.J. 2002. The amyloid hypothesis of Alzheimer's disease: progress and problems on the road to therapeutics. Science 297(5580), 353-6.

Hardy, J.A., Higgins, G.A. 1992. Alzheimer's disease: the amyloid cascade hypothesis. Science 256(5054), 184-5.

Harold, D., Abraham, R., Hollingworth, P., Sims, R., Gerrish, A., Hamshere, M.L., Pahwa, J.S., Moskvina, V., Dowzell, K., Williams, A., Jones, N., Thomas, C., Stretton, A., Morgan, A.R., Lovestone, S., Powell, J., Proitsi, P., Lupton, M.K., Brayne, C., Rubinsztein, D.C., Gill, M., Lawlor, B., Lynch, A., Morgan, K., Brown, K.S., Passmore, P.A., Craig, D., McGuinness, B., Todd, S., Holmes, C., Mann, D., Smith, A.D., Love, S., Kehoe, P.G., Hardy, J., Mead, S., Fox, N., Rossor, M., Collinge, J., Maier, W., Jessen, F., Schurmann, B., Heun, R., van den Bussche, H., Heuser, I., Kornhuber, J., Wiltfang, J., Dichgans, M., Frolich, L., Hampel, H., Hull, M., Rujescu, D., Goate, A.M., Kauwe, J.S., Cruchaga, C., Nowotny, P., Morris, J.C., Mayo, K., Sleegers, K., 
Bettens, K., Engelborghs, S., De Deyn, P.P., Van Broeckhoven, C., Livingston, G., Bass, N.J., Gurling, H., McQuillin, A., Gwilliam, R., Deloukas, P., Al-Chalabi, A., Shaw, C.E., Tsolaki, M., Singleton, A.B., Guerreiro, R., Muhleisen, T.W., Nothen, M.M., Moebus, S., Jockel, K.H., Klopp, N., Wichmann, H.E., Carrasquillo, M.M., Pankratz, V.S., Younkin, S.G., Holmans, P.A., O'Donovan, M., Owen, M.J., Williams, J. 2009. Genome-wide association study identifies variants at CLU and PICALM associated with Alzheimer's disease. Nature genetics 41(10), 1088-93. doi:10.1038/ng.440.

Jacobsen, J.C., Bawden, C.S., Rudiger, S.R., McLaughlan, C.J., Reid, S.J., Waldvogel, H.J., MacDonald, M.E., Gusella, J.F., Walker, S.K., Kelly, J.M., Webb, G.C., Faull, R.L., Rees, M.I., Snell, R.G. 2010. An ovine transgenic Huntington's disease model. Human molecular genetics 19(10), 1873-82. doi:10.1093/hmg/ddq063.

Jiang, Y., Xie, M., Chen, W., Talbot, R., Maddox, J.F., Faraut, T., Wu, C., Muzny, D.M., Li, Y., Zhang, W., Stanton, J.A., Brauning, R., Barris, W.C., Hourlier, T., Aken, B.L., Searle, S.M., Adelson, D.L., Bian, C., Cam, G.R., Chen, Y., Cheng, S., DeSilva, U., Dixen, K., Dong, Y., Fan, G., Franklin, I.R., Fu, S., Fuentes-Utrilla, P., Guan, R., Highland, M.A., Holder, M.E., Huang, G., Ingham, A.B., Jhangiani, S.N., Kalra, D., Kovar, C.L., Lee, S.L., Liu, W., Liu, X., Lu, C., Lv, T., Mathew, T., McWilliam, S., Menzies, M., Pan, S., Robelin, D., Servin, B., Townley, D., Wang, W., Wei, B., White, S.N., Yang, X., Ye, C., Yue, Y., Zeng, P., Zhou, Q., Hansen, J.B., Kristiansen, K., Gibbs, R.A., Flicek, P., Warkup, C.C., Jones, H.E., Oddy, V.H., Nicholas, F.W., McEwan, J.C., Kijas, J.W., Wang, J., Worley, K.C., Archibald, A.L., Cockett, N., Xu, X., Wang, W., Dalrymple, B.P. 2014. The sheep genome illuminates biology of the rumen and lipid metabolism. Science 344(6188), 1168-73. doi:10.1126/science.1252806.

Johnson, J.I., Sudheimer, K.D., Davis, K.K., Kerndt, G.M., Winn, B.M. The Sheep Brain Atlas. [Radiology Department, Neuroscience Program and Communications Technology Laboratory, Michigan State University, East Lansing, MI. https://msu.edu/ brains/index.html

Johnstone, E.M., Chaney, M.O., Norris, F.H., Pascual, R., Little, S.P. 1991. Conservation of the sequence of the Alzheimer's disease amyloid peptide in dog, polar bear and five other mammals by cross-species polymerase chain reaction analysis. Brain Res Mol Brain Res 10(4), 299-305.

Jolly, R.D., Janmaat, A., West, D.M., Morrison, I. 1980. Ovine ceroid-lipofuscinosis: a model of Batten's disease. Neuropathol Appl Neurobiol 6(3), 195-209.

Kelly, J.M., Kleemann, D.O., Walker, S.K. 2005. Enhanced efficiency in the production of offspring from 4-to 8-week-old lambs. Theriogenology 63(7), 1876-90.

Kendrick, K.M., da Costa, A.P., Leigh, A.E., Hinton, M.R., Peirce, J.W. 2001. Sheep don't forget a face. Nature 414(6860), 165-6. doi:10.1038/35102669.

Kragh, P.M., Nielsen, A.L., Li, J., Du, Y., Lin, L., Schmidt, M., Bogh, I.B., Holm, I.E., Jakobsen, J.E., Johansen, M.G., Purup, S., Bolund, L., Vajta, G., Jorgensen, A.L. 2009. Hemizygous minipigs produced by random gene insertion and handmade cloning express the Alzheimer's diseasecausing dominant mutation APPsw. Transgenic research 18(4), 545-58. doi:10.1007/s11248009-9245-4.

Levy-Lahad, E., Wasco, W., Poorkaj, P., Romano, D.M., Oshima, J., Pettingell, W.H., Yu, C.E., Jondro, P.D., Schmidt, S.D., Wang, K., et al. 1995. Candidate gene for the chromosome 1 familial Alzheimer's disease locus. Science 269(5226), 973-7.

Levy, E., Carman, M.D., Fernandez-Madrid, I.J., Power, M.D., Lieberburg, I., van Duinen, S.G., Bots, G.T., Luyendijk, W., Frangione, B. 1990. Mutation of the Alzheimer's disease amyloid gene in hereditary cerebral hemorrhage, Dutch type. Science 248(4959), 1124-6.

Mangialasche, F., Solomon, A., Winblad, B., Mecocci, P., Kivipelto, M. 2010. Alzheimer's disease: clinical trials and drug development. Lancet Neurol 9(7), 702-16. doi:S1474-4422(10)70119-8 [pii].

McGonigle, P. 2014. Animal models of CNS disorders. Biochemical pharmacology 87(1), 140-9. doi:10.1016/j.bcp.2013.06.016. 
Morton, A.J., Avanzo, L. 2011. Executive decision-making in the domestic sheep. PLoS One 6(1), e15752. doi:10.1371/journal.pone.0015752.

Morton, A.J., Rudiger, S.R., Wood, N.I., Sawiak, S.J., Brown, G.C., McLaughlan, C.J., Kuchel, T.R., Snell, R.G., Faull, R.L., Bawden, C.S. 2014. Early and progressive circadian abnormalities in Huntington's disease sheep are unmasked by social environment. Hum Mol Genet 23(13), 3375-83. doi:10.1093/hmg/ddu047.

Nelson, P.T., Saper, C.B. 1995. Ultrastructure of neurofibrillary tangles in the cerebral cortex of sheep. Neurobiology of aging 16(3), 315-23.

Perentos, N., Martins, A.Q., Watson, T.C., Bartsch, U., Mitchell, N.L., Palmer, D.N., Jones, M.W., Morton, A.J. 2015. Translational neurophysiology in sheep: measuring sleep and neurological dysfunction in CLN5 Batten disease affected sheep. Brain 138(Pt 4), 862-74. doi:10.1093/brain/awv026.

Portelius, E., Price, E., Brinkmalm, G., Stiteler, M., Olsson, M., Persson, R., Westman-Brinkmalm, A., Zetterberg, H., Simon, A.J., Blennow, K. 2011. A novel pathway for amyloid precursor protein processing. Neurobiology of aging 32(6), 1090-8.

Portelius, E., Tran, A.J., Andreasson, U., Persson, R., Brinkmalm, G., Zetterberg, H., Blennow, K., Westman-Brinkmalm, A. 2007. Characterization of amyloid beta peptides in cerebrospinal fluid by an automated immunoprecipitation procedure followed by mass spectrometry. Journal of proteome research 6(11), 4433-9. doi:10.1021/pr0703627.

Reid, S.J., Patassini, S., Handley, R.R., Rudiger, S.R., McLaughlan, C.J., Osmand, A., Jacobsen, J.C., Morton, A.J., Weiss, A., Waldvogel, H.J., MacDonald, M.E., Gusella, J.F., Bawden, C.S., Faull, R.L.M., Snell, R.G. 2013. Further Molecular Characterisation of the OVT73 Transgenic Sheep Model of Huntington's Disease Identifies Cortical Aggregates. Journal of Huntington's disease 2(3), 279-95. doi:10.3233/jhd-130067.

Sabbagh, J.J., Kinney, J.W., Cummings, J.L. 2013. Animal systems in the development of treatments for Alzheimer's disease: challenges, methods, and implications. Neurobiology of aging 34(1), 169-83. doi:10.1016/j.neurobiolaging.2012.02.027.

Saunders, A.M., Strittmatter, W.J., Schmechel, D., George-Hyslop, P.H., Pericak-Vance, M.A., Joo, S.H., Rosi, B.L., Gusella, J.F., Crapper-MacLachlan, D.R., Alberts, M.J., et al. 1993. Association of apolipoprotein $\mathrm{E}$ allele epsilon 4 with late-onset familial and sporadic Alzheimer's disease. Neurology 43(8), 1467-72.

Sawiak, S.J., Perumal, S.R., Rudiger, S.R., Matthews, L., Mitchell, N.L., McLaughlan, C.J., Bawden, C.S., Palmer, D.N., Kuchel, T., Morton, A.J. 2015. Rapid and Progressive Regional Brain Atrophy in CLN6 Batten Disease Affected Sheep Measured with Longitudinal Magnetic Resonance Imaging. PLoS One 10(7), e0132331. doi:10.1371/journal.pone.0132331.

Schellenberg, G.D., Montine, T.J. 2012. The genetics and neuropathology of Alzheimer's disease. Acta Neuropathol 124(3), 305-23. doi:10.1007/s00401-012-0996-2.

Sherrington, R., Rogaev, E.I., Liang, Y., Rogaeva, E.A., Levesque, G., Ikeda, M., Chi, H., Lin, C., Li, G., Holman, K., Tsuda, T., Mar, L., Foncin, J.F., Bruni, A.C., Montesi, M.P., Sorbi, S., Rainero, I., Pinessi, L., Nee, L., Chumakov, I., Pollen, D., Brookes, A., Sanseau, P., Polinsky, R.J., Wasco, W., Da Silva, H.A., Haines, J.L., Perkicak-Vance, M.A., Tanzi, R.E., Roses, A.D., Fraser, P.E., Rommens, J.M., St George-Hyslop, P.H. 1995. Cloning of a gene bearing missense mutations in early-onset familial Alzheimer's disease. Nature 375(6534), 754-60. doi:10.1038/375754a0.

Sjögren, M., Vanderstichele, H., Ågren, H., Zachrisson, O., Edsbagge, M., Wikkels $\varnothing$, C., Skoog, I., Wallin, A., Wahlund, L.-O., Marcusson, J. 2001. Tau and A 342 in cerebrospinal fluid from healthy adults 21-93 years of age: establishment of reference values. Clinical chemistry 47(10), 1776-81.

Sondergaard, L.V., Ladewig, J., Dagnaes-Hansen, F., Herskin, M.S., Holm, I.E. 2012. Object recognition as a measure of memory in 1-2 years old transgenic minipigs carrying the APPsw mutation for Alzheimer's disease. Transgenic research 21(6), 1341-8. doi:10.1007/s11248-012-9620-4. 
Vanderstichele, H., De Vreese, K., Blennow, K., Andreasen, N., Sindic, C., Ivanoiu, A., Hampel, H., Bürger, K., Parnetti, L., Lanari, A. 2006. Analytical performance and clinical utility of the INNOTEST ${ }^{\circledR}$ PHOSPHO-TAU (181P) assay for discrimination between Alzheimer's disease and dementia with Lewy bodies. Clinical Chemical Laboratory Medicine 44(12), 1472-80.

Vanmechelen, E., Vanderstichele, H., Davidsson, P., Van Kerschaver, E., Van Der Perre, B., Sjögren, M., Andreasen, N., Blennow, K. 2000. Quantification of tau phosphorylated at threonine 181 in human cerebrospinal fluid: a sandwich ELISA with a synthetic phosphopeptide for standardization. Neuroscience letters 285(1), 49-52.

Waldvogel, H.J., Curtis, M.A., Baer, K., Rees, M.I., Faull, R.L.M. 2007. Immunohistochemical staining of post-mortem adult human brain sections. Nat Protocols 1(6), 2719-32.

Weber, K., Pearce, D.A. 2013. Large animal models for Batten disease: a review. J Child Neurol 28(9), 1123-7. doi:10.1177/0883073813493666.

Youssef, S.A., Capucchio, M.T., Rofina, J.E., Chambers, J.K., Uchida, K., Nakayama, H., Head, E. 2016. Pathology of the Aging Brain in Domestic and Laboratory Animals, and Animal Models of Human Neurodegenerative Diseases. Vet Pathol 53(2), 327-48. doi:10.1177/0300985815623997.

Zetterberg, H., Skillback, T., Mattsson, N., Trojanowski, J.Q., Portelius, E., Shaw, L.M., Weiner, M.W., Blennow, K., Alzheimer's Disease Neuroimaging, I. 2016. Association of Cerebrospinal Fluid Neurofilament Light Concentration With Alzheimer Disease Progression. JAMA neurology 73(1), 60-7. doi:10.1001/jamaneurol.2015.3037. 